Egyptian

Orthodontic Journal

\title{
STUDY OF THE EFFECT OF TOPICALLY APPLIED ORAL GEL FORMULAS IN THE PREVENTION AND TREATMENT OF EARLY ENAMEL DECALCIFICATION (IN VITRO STUDY)
}

\author{
Abbas R. Zajer ${ }^{*}$ Hanaa S. Raslan ${ }^{* *}$ Hanan A. Ismail ${ }^{* * *}$ \\ Perihan N. Mohamed Ali ${ }^{* * *}$
}

ABSTRACT

The present study was designed to evaluate and compare the effect of Topacal C-5, a casein phosphoprotein amorphous calcium phosphate formulation and Home care $0.4 \%$ stannous fluoride gel in the prevention and treatment of white spot lesions. The first part of the study compared the effect of Topacal C-5 and stannous fluoride gel in preventing enamel demineralization. Thirty sound premolar teeth were divided into 3 equal groups of tens: Group I was treated with Topacal C-5, Group II was treated with stannous fluoride, and Group III was used as control group and received no treatment. Standard edgewise brackets were bonded to all teeth then the teeth were coated with an acid resistant varnish leaving about $2 \mathrm{~mm}$ occlusal and gingival to the bracket. The teeth were cycled between artificial saliva and artificial caries solution everyday for 35 days. Polarized light microscope pictures were taken and the depth and area of the demineralized zone was measured and compared statistically. The Topacal C-5 group showed the least depth and area of demineralization compared to the other two groups. The fluoride group also showed some

\footnotetext{
* Professor of Orthodontics, Faculty of Dentistry, Alexandria University.

** Professor of Oral Pathology, Faculty of Dentistry, Alexandria University.

*** Assistant Prof. of Orthodontics, Faculty of Dentistry, Alexandria University.

${ }^{* * * *}$ Student for Master Degree in Orthodontics, Faculty of Dentistry, Alexandria University.
} 
Egyptian

Orthodontic Journal

reduction in the depth and area of demineralization compared to the control group.

The second part of the study evaluated the effect of Topacal C-5 CPP-CP and stannous fluoride gel in treating white spot lesions. Artificial white spots were induced in 30 sound premolar teeth. The teeth were then divided into 3 groups: Group I was treated with Topacal C-5, Group II was treated with stannous fluoride, and Group III received no treatment and acted as a control group. The teeth were cycled between artificial saliva and caries solution for 4 weeks. Stereomicroscopic pictures were taken and a scoring system was used to evaluate the severity of the white spot lesions after two weeks and 4 weeks. The number of teeth which showed an improvement in the severity of the white spot lesions from the baseline was greater in the group treated with Topacal C-5 than the stannous fluoride and control group although the improvement was not statistically significant.

\section{INTRODUCTION}

Despite the recent advances in orthodontic materials and bonding techniques, the appearance of clinically detectable white demineralized areas continues to be a problem for both the clinicians and the patients during orthodontic treatment. ${ }^{(1)}$

Placing fixed orthodontic appliances hinders conventional oral hygiene and proper tooth cleansing by the patient leading to prolonged accumulation of food debris and bacterial plaque on the adjacent enamel surface. In addition, fixed appliances were found to physically alter the microbial environment causing both qualitative and quantitative changes of the dental plaque. Increased levels of Streptococcus mutans and lactobacilli were reported in the oral flora of orthodontic patients. ${ }^{(2,3)}$ These cariogenic bacteria produce organic acids leading to dissolution of the enamel and are associated with the initiation and further development of carious lesions.

The earliest sign of enamel decalcification is usually seen as white spots especially around the brackets, and may appear as early as after 4 weeks, which 
is the average time between regular orthodontic visits. ${ }^{(4)}$ The presence of these lesions is not typically noted until the removal of orthodontic appliances and although a saliva mediated remineralization after debonding might occur, the white spot areas often remain visible which is a disappointing result for the orthodontist.

The white appearance is due to an optical phenomenon caused by mineral loss in the surface or subsurface of enamel. Thus decalcification prophylaxis and oral hygiene measure are particularly important during the therapy. Numerous proposals have been recommended to control demineralization problems. Topically applied fluoride preparations and the casein phosphoprotein preparations are some of the proposed strategies.

A research attempted by McFarland and Shannon (1974) ${ }^{(5)}$ concluded that brushing with $\mathrm{SnF}_{2}$ gel for 28 days was found to reduce the solubility of enamel by $27.3 \%$ and more than doubled the fluoride concentration in the outer enamel .

Boyd (1993) (6) compared the effectiveness of: a) $1100 \mathrm{ppm}$ fluoride toothpaste used alone (control group), or together with b) $0.05 \%$ sodium fluoride $(\mathrm{NaF})$ rinse used once daily or c) $0.4 \%$ stannous fluoride gel $\left(\mathrm{SnF}_{2}\right)$ twice daily in controlling the enamel decalcification. Results showed that the rinse and gel groups demonstrated lower demineralization than the control groups. This indicated that the fluoride toothpastes should be associated with either $0.05 \% \mathrm{NaF}$ mouth rinse or $0.4 \% \mathrm{SnF}_{2}$ gel for more reduction of decalcification.

Recently, an increasing amount of data and information demonstrating the bioactive role for dairy components in adults including a role in the prevention of dental caries were reported. Some studies proved that milk, ice cream, and cheese lowered incidence of dental caries. ${ }^{(7,8,9,10)}$ Milk contains factors that have anticariogenic properties: calcium, phosphate, casein, and lipids. Specifically, the casein fraction has been the focus for researchers investigating cariogenicity prevention.

Schupbach and his coworkers (1996) ${ }^{(11)}$ tested the hypothesis that milk components are incorporated into the salivary pellicle, thereby reducing the adherence of S. sobrinus. The resulting pellicle was washed and incubated with caseinoglycomacropeptide (CGMP) and/or caseinophosphopeptide (CPP). Electron microscopy concluded that the incorporation of CGMP and/or CPP into salivary pellicles reduced the adherence of both $\mathrm{S}$. sobrinus and $\mathrm{S}$. mutans significantly. The modified cariogenic potential of this film was found to be a result of the ecological shifts and increased remineralization potential of this biofilm. 
A randomized double-blinded cross over study was conducted by Reynolds and his co-workers (2003) ${ }^{(12)}$. They investigated whether short-term (5 days') use of a CPP-ACP-containing mouth rinse could considerably increase the level of calcium and inorganic phosphate in the supragingival plaque compared with an unstabilized calcium phosphate mouth rinse. The CPP-ACP particles were observed to be immunolocalized to the surfaces of bacterial cells as well as the intercellular matrix. The results verified that only the CPP-ACPcontaining mouth rinses significantly increased the plaque calcium and inorganic phosphate levels thereby reducing the risk of enamel demineralization.

Despite the clinician's best intentions, post-treatment white spot areas of demineralization sometimes still persist as a problem after the removal of the fixed orthodontic appliances. Various studies were made to find the best treatment modalities of these unaesthetic lesions.

Oggard and his associates $\left(1988^{(13)}\right.$ performed a study where the effect of fluoride mouth rinse and a low $\mathrm{pH}$ fluoride solution on lesion development during treatment with fixed orthodontic appliances was investigated. They concluded that daily mouth rinse with neutral $0.2 \% \mathrm{NaF}$ solution may decrease but not completely inhibit caries lesion development during treatment, while a fluoride solution with low $\mathrm{pH}$ may completely inhibit the lesion development underneath orthodontic bands.

Delbem and Cury (2002) ${ }^{(14)}$ performed a study to evaluate the effect of time of fluoride gel application (acidulated or neutral), on in vitro enamel resistance to demineralization and fluoride uptake. Results showed that acidulated fluoride gel formed more fluoride in enamel than neutral gel and was also more efficient in reducing the demineralization of the enamel blocks submitted to a cariogenic challenge than the neutral gel. It was concluded that the time of application was significant in terms of fluoride uptake, although it did not render the enamel more resistant to demineralization.

Alternatively, preparations other than fluorides were used in treatment and inhibition of areas of demineralization. Studies confirmed that besides the anticariogenic role of milk and casein complexes, they had a great effect in the inhibition and remineralization of initial carious lesions.

Reynolds in $1997^{(15)}$ designed an in vitro study to examine the effect of casein phosphoprotein-calcium phosphate concentration (CPP-CP) on the remineralization of enamel subsurface lesions in human third molar teeth. It was found out that the CPP showed significantly high rates of enamel remineralization of the enamel lesions. 
Cai and his co-workers (2003) ${ }^{(16)}$ determined the effect of CPP-ACP on remineralization of subsurface enamel lesions by incorporating it into a sugarfree lozenge (pressed mint tablet). The level of remineralization was computed using micro radiography and densitometric image analysis. The study demonstrated that CPP-ACP lozenges can be a suitable vehicle for promoting remineralization as they significantly increased enamel subsurface lesion remineralization relative to the control sugar free lozenges.

Attia and Fayed $(2005)^{(17)}$ investigated the effect of phosphoprotein calcium phosphate complexes ( Topacal C-5) on etched enamel surfaces and their remineralizing action. The scanning electron microscope results showed that Topacal C-5 had a significant remineralizing effect on the etched enamel which was comparable to that of sound enamel surfaces.

This study was attempted in order to:

1- Compare the efficiency of Topacal C-5 casein phosphoprotein - calcium phosphate and Home Care $0.4 \%$ Stannous fluoride gel in the prevention of demineralization adjacent to directly bonded orthodontic brackets.

2- Examine and compare the effect of Topacal C-5 casein phosphoprotein calcium phosphate and Home Care $0.4 \%$ Stannous fluoride gel in the management and treatment of artificial early non-cavitated enamel decalcification (white spots).

\section{Materials and Methods:}

The material of this comparative study consisted of 60 premolar teeth extracted for orthodontic purposes from adolescent patients.The teeth selected for the study were sound, caries-free and showed no areas of decalcification .

After extraction; the teeth were thoroughly rinsed with running water and stored in $10 \%$ formaldehyde solution till the study was initiated thereby preventing dehydration.

The teeth were then divided into two groups each consisting of 30 teeth and the study was done in two parts: 
I- The first part: to compare the efficiency of two topically applied formulations in the prevention of demineralization around directly bonded brackets.

II- The second part: to evaluate and determine the effect of these two topically applied formulations in the treatment and management of artificially induced white enamel spots.

During the study cycling between artificial saliva ${ }^{(18)}$ and artificial caries solutions was performed.

Part I- Comparison of the efficiency of Topacal C-5 \& Stannous Fluoride gel in prevention of demineralization adjacent to orthodontic brackets.

In this part of the study, thirty premolar teeth were used after cleansing and polishing a window, the size of an orthodontic bracket base was cut out from a piece of adhesive tape. The tape was placed with the window centered on the facial surface on the tooth to limit unintentionally acid etching of the entire enamel surface which could initiate enamel demineralization.

The enamel, exposed by the window tape, was etched for 30 seconds with $37 \%$ orthophosphoric acid gel, rinsed with water for the same amount of time and thoroughly dried with compressed air.

Standard edgewise premolar metal brackets were bonded to all teeth using a chemically cured, non-fluoride releasing composite resin following the manufacturer's instructions. The brackets were positioned with firm pressure and excess resin flash was removed from around each bracket base with a dental scaler.

Twenty minutes after bonding, the adhesive tape was removed from each tooth. The teeth were then painted with a thin coat of acid resistant varnish covering all the surfaces of the teeth except a $2 \mathrm{~mm}$ area directly adjacent to the bracket.

The teeth were further subdivided into 3 equal groups each consisting of 10 teeth: 
- Group 1: The exposed enamel surfaces of the teeth in this group were treated twice daily with Topacal C-5 casein phospho-protein preparation* according to the manufacturer's recommendations.

- Group 2: The exposed enamel surfaces of the teeth in this group were treated with topical stannous fluoride gel ${ }^{* *}$ which was applied once daily according to the manufacturer's recommendations.

- Group 3: The control group received no further treatment during the study.

Each group was stored in separate beakers containing $200 \mathrm{ml}$ artificial saliva solution. After $12 \mathrm{~h}$, cycling between artificial saliva and artificial caries challenge solution was initiated where the teeth were immersed for $1 \mathrm{~h}$ in beakers containing $200 \mathrm{ml}$ of artificial caries solution twice daily. (one for each group). Both solutions were stored at room temperature and changed every three days. The teeth were cycled between artificial saliva and artificial caries challenge for 35 days. At day 35, all the teeth were removed from saliva solution, dried thoroughly then the brackets debonded.

The teeth were then sectioned longitudinally in a buccolingually direction using a water-cooled diamond disk and then further reduced by hand grinding on polishing boards until a thickness of about $100 \mu \mathrm{m}$ was obtained. Sections were then washed with deionized water, and mounted longitudally on glass cover slides. The teeth in the three groups were then examined under polarized light microscope and photographed with X 50 magnification.

To calculate the depth measurements, transverse lines perpendicular to the enamel surface and extending to the deepest points of the lesion where pseudo isotropy occurred were drawn and measured using a digital caliber. Three representative measurements from the surface of the lesion to its depth were taken for each section and the mean depth calculated The real depth was calculated in mm using a scale 1:50 and then converted to $\mu \mathrm{m}$ by multiplying it by $10^{3}$. (Fig 1 )

The standardized area of the lesion between these three depth measurements was also calculated using a computerized software (Auto CAD 2004). The real area was calculated in mm using a scale 1:2500 and converted to $\mu \mathrm{m}$ by multiplying it by $10^{6}$.

\footnotetext{
* Topacal C-5, NSI Dental Pty Ltd, Australia

** Home Care Fluoride Treatment Gel, 0.4\% Stannous Fluoride, Alpha-Dent, USA
} 


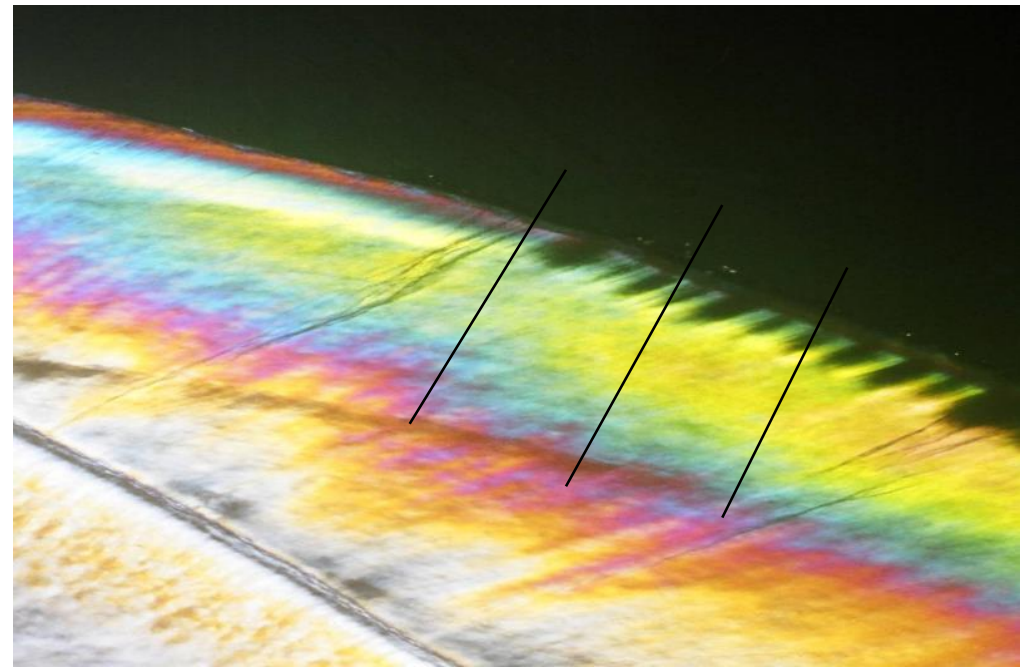

Fig 1: A polarized light microscopic picture (with magnification $50 \mathrm{x}$ ) showing the three transverse lines drawn from the surface of the lesion to its depth.

Part II- Comparison of the effect of Topacal C-5 \& Stannous Fluoride gel in the treatment and management of artificially induced white spot lesions.

The other sample of 30 extracted premolar teeth were used in this part of the study after cleansing and polishing as fore mentioned. All the teeth were covered with an adhesive tape leaving a small window on the buccal surface and then immersed in the artificial caries solution for 3 weeks until visible artificial white spots were formed (Fig 2).

The adhesive tape was removed and the teeth washed under running water for $60 \mathrm{sec}$ and dried with moisture and oil free light jet of air for $15 \mathrm{sec}$ and the teeth were examined visually and photographed by a stereomicroscope.

A scoring system was used to assess the severity of the artificial white spot lesions as follows ${ }^{(1)}$ 
Egyptian

Orthodontic Journal

\begin{tabular}{|l|l|}
\hline \multicolumn{2}{|l|}{} \\
\hline Score 0 & No visible white spot \\
\hline Score 1 & Slight visible white spot \\
\hline Score 2 & Excessive visible white spot \\
\hline Score 3 & White spot with cavitation \\
\hline
\end{tabular}

Immediately after demineralization and formation of the artificial white spots all the teeth had a baseline score 2 showing excessive visible white spot formation.

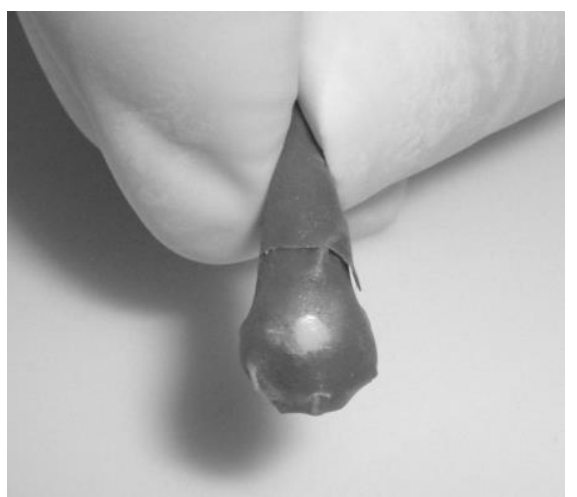

Fig 2: The tooth covered with an adhesive tape leaving a small window on the buccal surface

The sample was then subdivided into 3 equal groups, each consisting of 10 teeth.

- Group 1: The teeth were treated twice daily with Topacal C-5 which was applied topically to the white spot area.

- Group 2: The teeth were treated once daily with stannous fluoride topical gel which was applied to the white spot area.

- Group 3: The control group, where no treatment of the white spot area was done. 
The three groups were stored in separate beakers containing artificial saliva which was changed every 3 days and cycling with artificial caries solution was attempted for one hour twice daily as described previously. The white spot areas were further examined visually and photographed by stereomicroscope after a follow up period of two weeks and four weeks of application of the topical preparations.

\section{Statistical Methodology:}

The statistical analysis for this study was done using Statistical Package for Social Sciences software (SPSS) version 9.

In the first part of the study the mean depth and area of demineralization measured in each of the three groups was analyzed and compared using F-test. Post hoc pairwise comparison of different pairs of groups was done using Tukey's multiple comparison tests.

In the second part of the study, the change in the scoring of white spots in each of the study groups through time was compared using Wilcoxon Signed Rank tests. The chi square test was also used to compare the severity of white spot lesions among the three groups at different follow up periods.

A 5\% level was predetermined as a level of significance in all statistical significant tests used in the study.

\section{RESULTS}

The results of this in vitro study will be presented in two parts:

Part I: a) The histological findings of the polarized light microscope pictures.

b) Evaluation of the depth and area.

Part II: Assessment and scoring of the white spot lesions

\section{Ia) Histological findings of the polarized light microscope pictures.}

The histological results of the polarized light microscope sections demonstrated variations in the depths and areas of the demineralized lesions among the three groups. 
Group I which was treated with Topacal C-5 appeared to have the least depths of demineralized areas. This was represented by the positive form birefringence (where the different zones show heterogeneous colours) in the body of the lesion (subsurface area) while the surface seemed to have negative form birefringence (showing a homogeneous yellow color) and appeared unaffected in most sections. Evidences of starting remineralization with less porous tissue also appeared in this group. (Fig3)

Group II which was treated with the stannous fluoride gel showed comparatively increased depths of the demineralized areas, affecting the surface and body of the lesion and extending deeper into the enamel which was indicated by the positive form birefringence. The area of demineralization was found to be greater in this group than the first group. (Fig4)

Group III which was the control group showed the deepest measurements of the demineralized lesion extending in some sections to the full enamel thickness to the underlying dentin as indicated by the positive form of birefringence. Darkness of the subsurface zone and blurring of the Striae of Retzius were apparent. (Fig5)

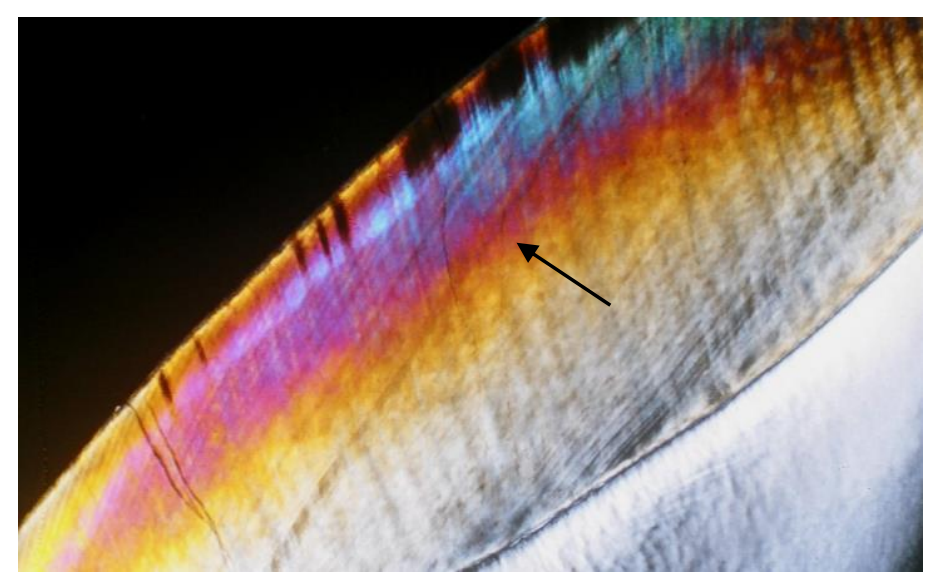

Fig3: A polarized light microscope picture (with magnification 50X) of the Topacal C-5 group showing the demineralization affecting the subsurface zones as indicated by the change from positive to negative form birefringence (indicated by the arrow). 


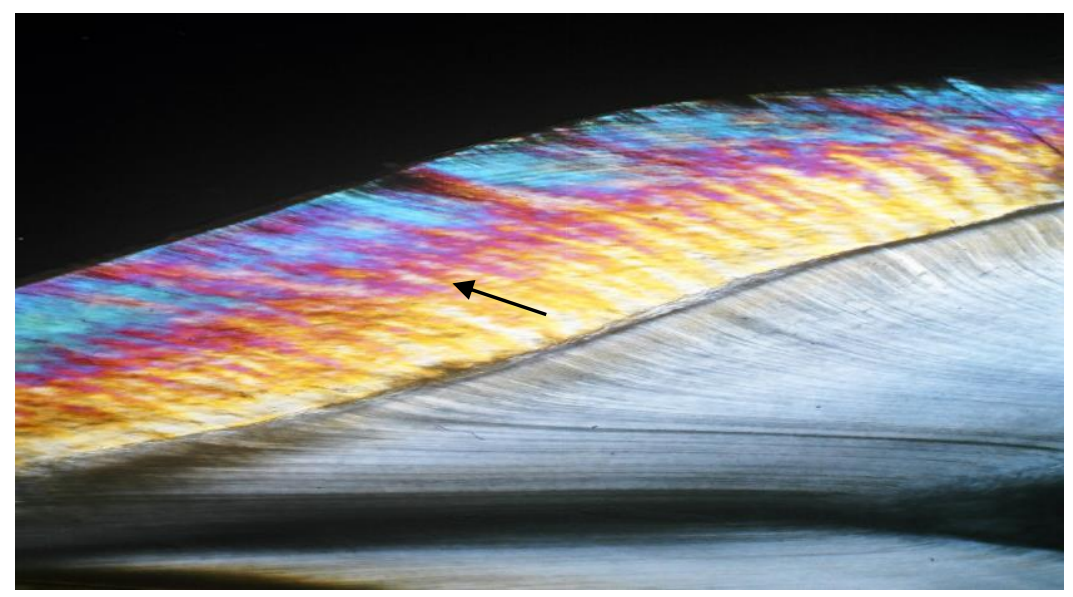

Fig4: A polarized light microscope picture (with magnification 50X) of the Stannous fluoride group showing the demineralization extending deeper into the subsurface and body of lesion as indicated by change from positive to negative form birefringence ( represented by the arrow).

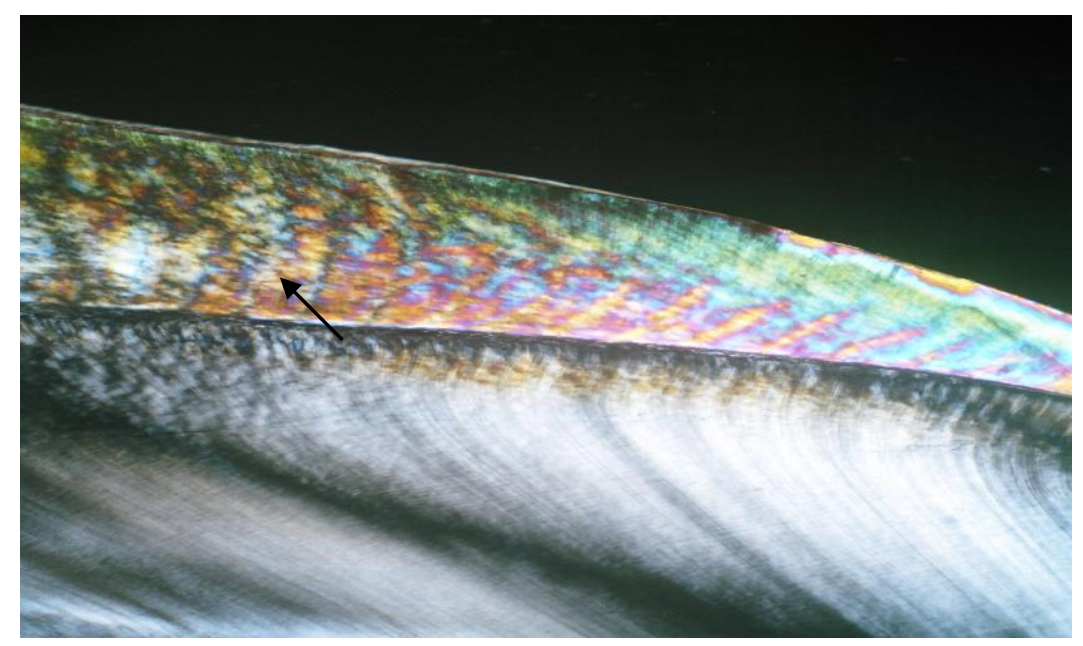

Fig5: A polarized light microscopic picture (with magnification 50X) of the Control group showing the increased depth of demineralization extending to the full enamel thickness with darkness of subsurface zones. (represented by the arrow) 
Egyptian

Orthodontic Journal

\section{Ib) Evaluation of the depth and area of lesions:}

Comparison of mean area of demineralization among the three study groups.

The comparison of the mean area of demineralization in $\mu \mathrm{m}^{2} \times 10^{3}$ among the three study groups is presented in Table 1. The largest mean area was found in the control group, followed by the stannous fluoride group while the Topacal group specimens showed the smallest area $\left(830.85,517.12\right.$ and $249.18 \mu \mathrm{m}^{2} \mathrm{X}$ $10^{3}$ respectively). The difference between the three groups was statistically significant $(F=31.53, \mathrm{p}<0.0001)$.

Table1: Basic statistics showing the comparison of the mean area of demineralization in $\mu \mathrm{m}^{2} \times 10^{3}$ between three study groups

\begin{tabular}{||l|c|c|c||}
\hline \hline GROUP & TOPACAL & $\begin{array}{c}\text { STANNOUS } \\
\text { FLUORIDE } \\
\mathrm{N}=10\end{array}$ & CONTROL \\
\hline Min- $\max$ & $96.06-493.03$ & $343.94-819.82$ & $604.94-1087.16$ \\
\hline Mean & 249.18 & 517.12 & 830.85 \\
\hline SD & 127.31 & 152.74 & 202.74 \\
\hline F test & 31.53 & & \\
\hline P value & $<0.0001^{*}$ \\
\hline
\end{tabular}

*: statistically significant at $\mathrm{p} \leq 0.05$

Comparison of mean depth of demineralization among the three study groups.

The comparison of mean depth of demineralization in $\mu \mathrm{m}$ among the three study groups is shown in Table 2. Deepest lesions were found in the control group, followed by the stannous fluoride group while the shallowest lesions found in the Topacal group (1058.26, 627.44 and $382.02 \mu \mathrm{m}$ respectively). The difference between the three groups was statistically significant $(\mathrm{F}=43.72, \mathrm{p}<0.0001)$. 
Egyptian

Orthodontic Journal

Table 2: Basic statistics showing the comparison of the mean depth of demineralization in $\mu \mathrm{m}$ between the three study groups.

\begin{tabular}{||l|c|c|c||}
\hline \hline GROUP & $\begin{array}{c}\text { TOPACAL } \\
\mathrm{N}=10\end{array}$ & $\begin{array}{c}\text { STANNOUS FLUORIDE } \\
\mathrm{N}=10\end{array}$ & $\begin{array}{c}\text { CONTROL } \\
\mathrm{N}=10\end{array}$ \\
\hline Min- $\max$ & $256.00-576.40$ & $408.84-842.20$ & $822.80-1511.40$ \\
\hline Mean & 382.02 & 627.44 & 1058.26 \\
\hline SD & 111.24 & 143.61 & 217.75 \\
\hline F test & 43.72 & & \\
\hline P value & $<0.0001 *$ & & \\
\hline
\end{tabular}

*: statistically significant at $\mathrm{p} \leq 0.05$

\section{II) Assessment of the white spot lesion formation:}

This study evaluated in vitro the severity of artificial white spots. The lesions were assessed at baseline, after two weeks and after 4 weeks.

At baseline, all lesions had score 2 (excessive lesions).

Assessment of Topacal C-5 group at baseline, after two weeks and after four weeks follow up period.

Figure 6 shows the stereomicroscopic pictures of the Topacal C-5 group.

The number of excessive spots (score 2) decreased from ten at baseline to four after two weeks and further to three by the end of the study period after four weeks. There was an improvement in some of the cases scored as excessive at baseline so that there were six cases scored as slight (score 1) after two weeks and even one case with complete healing (score 0) after four weeks. The changes in lesion severity from baseline to scores after two weeks and scores after four weeks were statistically significant $(Z=2.45$ and 2.53 respectively). 


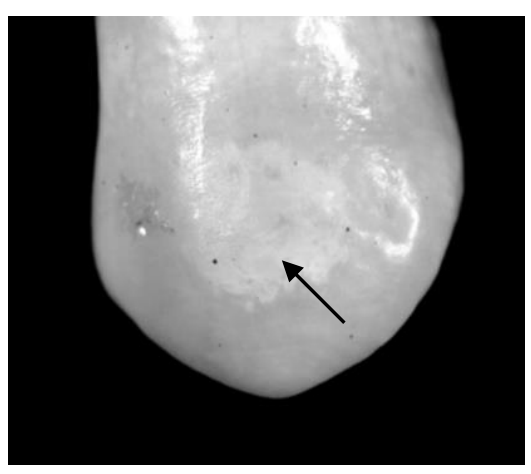

Before treatment

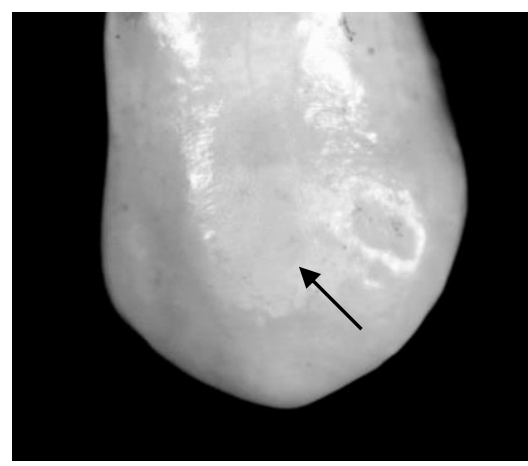

2 weeks

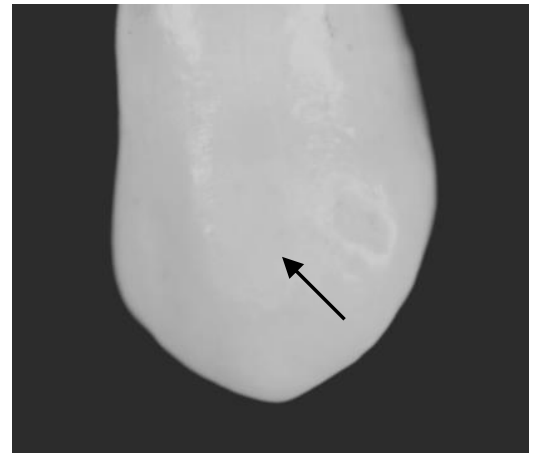

4 weeks

Fig 6: A stereomicroscopic picture of a premolar in the Topacal group showing slight white spot (score 1) after 2 weeks and the disappearance of the white spot lesion (score 0) after 4 weeks.

Assessment of Stannous Fluoride group at baseline, after two weeks and after four weeks follow up period.

The number of excessive spots (score 2) decreased from ten at baseline to seven after two weeks and further to five by the end of the study period after four weeks. There was an improvement in some cases from the baseline score (score 2) where three cases showed slight white spots (score 1) after two weeks and increased to five cases after four weeks. There were no cases with complete healing by the end of the study after four weeks. The change in the severity of white spot from baseline to scores after two weeks was not statistically significant $(Z=1.73, p=0.08)$, while the change in scores after four weeks was statistically significant $(Z=2.24, p=0.03)$. 


\section{Assessment of Control group at baseline, after two weeks and after four weeks follow up period.}

The number of excessive spots (score 2) decreased from ten at baseline to seven after two weeks and further to six by the end of the study period after four weeks. There was an improvement in some of the cases from the baseline score (score 2). Three cases were scored as slight (score 1) after two weeks which increased to four cases after four weeks. There were no cases with complete healing by the end of the study after four weeks. The change in lesion severity from baseline to scores after two weeks was not statistically significant $(Z=1.73, p=0.08)$, while the change in scores after four weeks was statistically significant $(\mathrm{Z}=2.00, \mathrm{p}=0.05)$.

\section{Comparison of the severity of white spots among the three study groups after two weeks.}

Results of examination after two weeks are shown in Table 5. Seven cases (70\%) in both the stannous fluoride and control groups were scored as excessive (score 2), with the remaining three cases in either group (30\%) turning to slight lesions (score 1). In the Topacal group, six cases (60\%) turned to slight lesions (score 1), while only 4 cases $(40 \%)$ were still excessive (score 2 ). Thus, the Topacal C-5 showed an increase in the number of teeth with improvement in the scoring of the white spots from baseline than the fluoride and control groups. The difference between the three groups however was not statistically significant. $\left(\chi^{2}=2.50, \mathrm{p}=0.2\right)($ Fig7 $)$

Table 3: Comparison of the severity of white spots among the three studied groups after two weeks.

\begin{tabular}{|c|c|c|c|c|}
\hline \multirow[b]{2}{*}{ WHITE SPOTS } & \multicolumn{3}{|c|}{ GROUPS } & \multirow{2}{*}{$\begin{array}{l}\text { TOTAL } \\
\mathrm{N}(\%)\end{array}$} \\
\hline & $\begin{array}{c}\text { Topacal } \\
\mathrm{N}(\%) \\
\end{array}$ & $\begin{array}{c}\text { Stannous fluoride } \\
\mathrm{N}(\%)\end{array}$ & $\begin{array}{l}\text { Control } \\
\mathrm{N}(\%) \\
\end{array}$ & \\
\hline $\begin{array}{c}\text { Score } 1 \\
\text { (slight white spot) }\end{array}$ & $6(60)$ & $3(30)$ & $3(30)$ & $12(40)$ \\
\hline $\begin{array}{c}\text { Score } 2 \\
\text { (excessive white spot) }\end{array}$ & $4(40)$ & $7(70)$ & $7(70)$ & $18(60)$ \\
\hline Total & $10(100)$ & $10(100)$ & $10(100)$ & $30(100)$ \\
\hline$\chi^{2}$ & \multicolumn{3}{|c|}{2.50} & \\
\hline$P$ value & \multicolumn{3}{|c|}{$0.29 \mathrm{NS}$} & \\
\hline
\end{tabular}




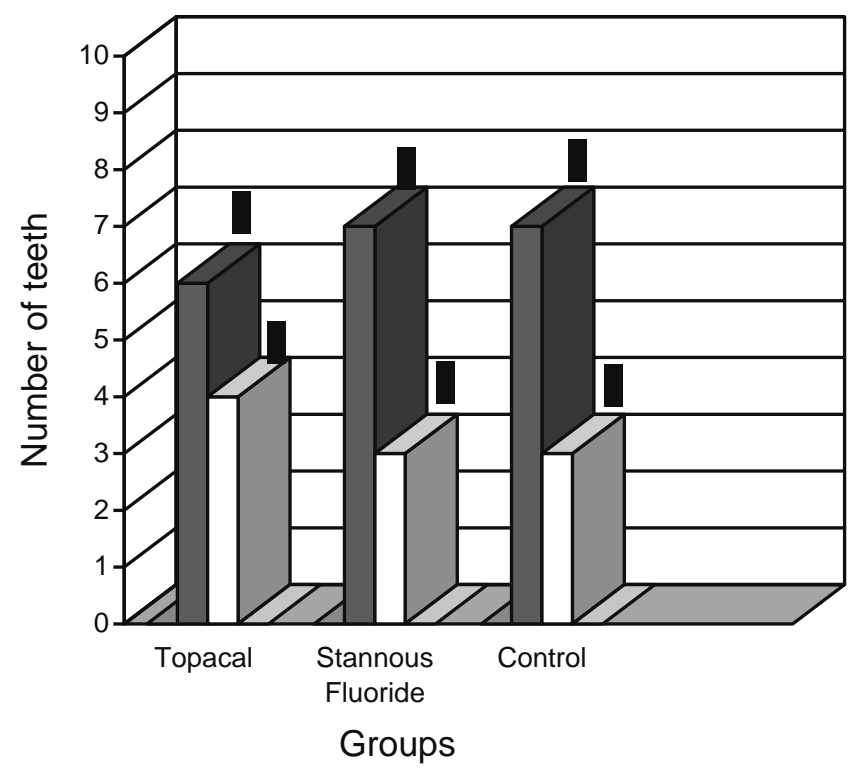

Fig7: A bar graph showing the number of teeth having each score among the three study groups after 2 weeks.

Comparison of the severity of white spots among the three study groups after 4 weeks.

Table 4 shows the comparison of the severity of white spots among the three study groups after 4 weeks. Sixty percent of the control group lesions were excessive (score 2) compared to $50 \%$ of the stannous fluoride group and $30 \%$ of the Topacal group. On the contrary, one case in the Topacal group was completely treated compared to none in either the stannous fluoride or the control groups. Thus, the Topacal group had a higher number of teeth with lower scores (score $0 \& 1$ ) than the other two groups. The difference between the three groups, however, was not statistically significant $\left(\chi^{2}=3.40, p=0.49\right)$. (Fig 8) 
Egyptian

Orthodontic Journal

Table 4: Comparison of the severity of white spots among the three study groups after 4 weeks.

\begin{tabular}{|c|c|c|c|c|}
\hline \multirow[b]{2}{*}{ WHITE SPOTS } & \multicolumn{3}{|c|}{ GROUPS } & \multirow{2}{*}{$\begin{array}{l}\text { TOTAL } \\
\text { N (\%) }\end{array}$} \\
\hline & $\begin{array}{l}\text { Topacal } \\
\mathrm{N}(\%)\end{array}$ & $\begin{array}{c}\text { Stannous fluoride } \\
\mathrm{N}(\%)\end{array}$ & $\begin{array}{l}\text { Control } \\
\mathrm{N}(\%)\end{array}$ & \\
\hline $\begin{array}{c}\text { Score } 0 \\
\text { (no white spot) }\end{array}$ & $1(10)$ & - & - & $1(3.3)$ \\
\hline $\begin{array}{c}\text { Score } 1 \\
\text { (Slight white spot) }\end{array}$ & $6(60)$ & $5(50)$ & $4(40)$ & $15(50)$ \\
\hline $\begin{array}{c}\text { Score } 2 \\
\text { (Excessive white spot) }\end{array}$ & $3(30)$ & $5(50)$ & $6(60)$ & $14(46.7)$ \\
\hline Total & $10(100)$ & $10(100)$ & $10(100)$ & $30(100)$ \\
\hline$\chi^{2}$ & \multicolumn{3}{|c|}{3.40} & \\
\hline $\mathrm{P}$ value & \multicolumn{3}{|c|}{$0.49 \mathrm{NS}$} & \\
\hline
\end{tabular}

$\chi^{2}:$ chi square test, NS: not statistically significant

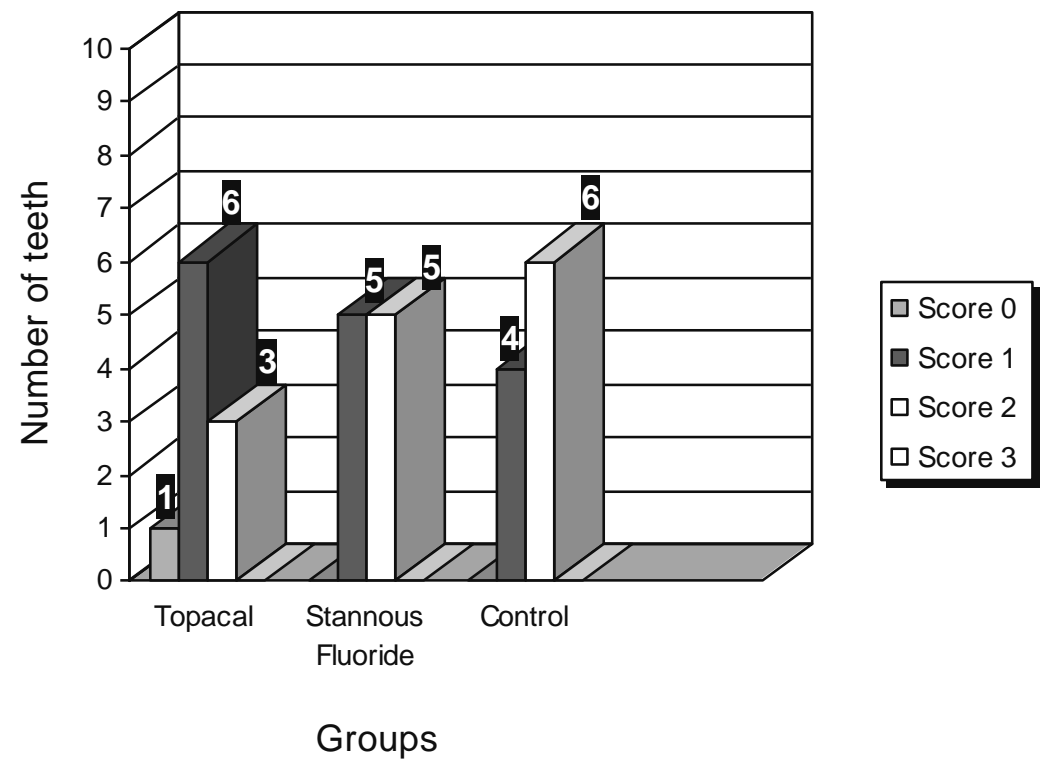

Fig8: A bar graph showing the number of teeth having each score among the three study groups after four weeks. 
Egyptian

Orthodontic Journal

\section{DISCUSSION}

Much effort is now being channeled into reducing white spot lesions which are unaesthetic, unhealthy and potentially irreversible. Several forms of fluorides have been widely used as caries preventive agents to reduce demineralization around orthodontic appliances, but still there are no evidences that any method is superior to the other. Recently, casein phosphoprotein formulations, incorporated it into mouthwashes, chewing gums and lozenges, were introduced as a new method of reducing enamel demineralization.

The stannous fluoride gel was selected in this study instead of other topically applied fluoride rinses, toothpastes or dentifrices as the gels are directly applied to the tooth and remain contacting the enamel surface for a longer duration. The $0.4 \%$ stannous fluoride gel contains about 1000 parts per million fluoride ions. ${ }^{(19)}$

In the first part of the study, the efficiency of Topacal C-5 and stannous fluoride gel in the prevention and inhibition of enamel demineralization was tested. We designed the experiment to last for 35 days which was approximately the time reported in previous studies for white spots to develop (4 weeks). ${ }^{(4)}$

The results of our study showed that the group treated with Topacal C-5 casein-phosphoprotein amorphous calcium phosphate (CPP-ACP) illustrated the least demineralization with evidences of some remineralization in comparison to the fluoride gel and the control group. These findings correlated with a study made by Reynolds (1987) ${ }^{(20)}$ who found that two exposures of CPP-ACP solution per day considerably reduced the enamel mineral loss relative to the opposite untreated side.

Similarly, Roberts $(1995)^{(21)}$ pointed out a significantly greater retention of calcium in enamel pretreated with CPP when subjected to demineralizing conditions. He deduced that CPP may show an anti-caries effect through inhibiting the demineralization of enamel subjected to acid challenge. A possible explanation to these results was proposed by Aimutis ${ }^{(22)}$ who suggested that CPP binds to the calcium and phosphates stabilizing amorphous calcium phosphate (ACP) at the tooth surface to provide a reservoir of these ions which are released as the $\mathrm{pH}$ in the plaque decreases. Consequently, an over saturation with minerals is maintained, thus buffering the plaque $\mathrm{pH}$ which reduces demineralization and also provides ions for tooth enamel remineralization to occur. The topical anticariogenic action of CPP was attributed by Reynolds, 
Riley and Storey (1982) $)^{(23)}$ to casein; the bovine milk phosphoprotein stating that the two major fractions of casein ( alpha $\mathrm{s}_{\mathrm{s}}$ and beta-casein ) bind strongly to hydroxyapatite thus reducing the dissolution rate of mineral.

The stannous fluoride group in our study also showed lower depth and area of demineralization compared to the control group. The literature has thoroughly demonstrated that fluorides have a well known effect in prevention of demineralization although this effect is still controversial. Authors ${ }^{(13)}$ explained that topical fluorides react to form calcium fluoride which remains persistent on the enamel surface for several weeks. This is caused by the common ion effects and the adsorption of phosphate ions and protein molecules onto calcium fluoride. The calcium fluoride deposit forms an acid resistant protection against cariogenic challenges and also serves as a $\mathrm{pH}$ controlled reservoir of fluoride available for remineralization and inhibition of demineralization. Fluorides, by itself, were not found to prevent the caries process from occurring but it only affected its rate of progression. During cariogenic challenges, the calcium fluoride formation in the lesions may be transformed into fluorapatite thus inhibiting further lesion progression. However, this slows down the remineralization process. Based on this explanation, the increase in the depths and area of demineralization in the stannous fluoride group in comparison to the group treated with Topacal C-5 may be understood.

\section{II- Management and treatment of artificial white spot lesions.}

An artificial caries solution which resembled the cariogenic acidic challenge occurring in the oral cavity was used in this study to induce artificial white spots on the buccal surface of sound premolar teeth. The well controlled buffer system was selected rather than the acid gel and the diphosphonate surfa0ce dissolution inhibitor systems which were used in previous studies. ${ }^{(24)}$ This system consists of an acetic acid buffer solution partially saturated with calcium and phosphate and adjusted to $\mathrm{pH} 5$ by potassium hydroxide $(\mathrm{KOH})$. Scanning electron microscopic (SEM) examination of lesions created with this system revealed a great similarity to naturally occurring carious lesions. ${ }^{(18)}$

Evaluation of the white spot lesions showed that after both two and four weeks, the group treated with Topacal C-5 demonstrated a greater number of teeth showing an improvement in the severity of white spot areas than the stannous fluoride and control groups. This indicated remineralization of the incipient lesions. However, the difference between the three groups wasn't 
Egyptian

Orthodontic Journal

statistically significant which might be attributed to the small sample size used (10 for each group).

The remineralizing effect of Topacal C-5 observed in our study was found to be in accordance with the findings of researches made by Reynolds (1997) ${ }^{(15)}$ and Shen (2001) ${ }^{(25)}$. These authors stated that the addition of CPP-ACP to gums resulted in a dose-related remineralization in the enamel subsurface lesions which may reach up to $152 \%$. They further described that the CPP acts as a calcium phosphate reservoir by stabilizing calcium phosphate in the solution, and maintains high concentration gradient of calcium and phosphate ions and ion pairs into the subsurface lesions thus effecting high rates of enamel remineralization. Similarly, Attia \& Fayed (2005) ${ }^{(17)}$ supported the results of our study. They concluded that Topacal C-5 had a significant remineralizing effect on the etched enamel. This was apparent by scanning electron microscope (SEM) pictures which showed complete remineralization and repair of the lesions.

Concerning the stannous fluoride group, some teeth showed a clinical improvement of the white spot lesion scoring. This appeared to be significant from the baseline score after four weeks. Although the fluorides have a well know cariostatic role, there is still a debate on the efficiency of fluorides in the treatment of demineralization and on the optimal concentration required to obtain this effect. Oggard et al ${ }^{(4)}$ and Ten Cate and Duijster $(1982)^{(26)}$ noted that treatment of visible white lesions with concentrated fluoride agents arrested remineralization after some time and the lesions were hardly further demineralized or remineralized.

In an attempt to overcome lesion consolidation, several studies ${ }^{(27)}$ recommended the use of low fluoride concentrations or low dose fluoride applications to enhance subsurface remineralization. Linton ${ }^{(27)}$ mentioned in her study that a 50 ppm fluoride mouth rinse had a higher efficiency for remineralization than a control solution or a regular mouthwash containing $250 \mathrm{ppm}$ fluorides. On the other hand, Willmot $(2003){ }^{(28)}$ had a different view stating that no clinical advantage or therapeutic effect was found in his study by the use of low fluoride formulation of toothpastes or mouth rinses. Taking into consideration that $\mathrm{SnF}_{2}$ contains $1000 \mathrm{ppm}{ }^{(21)}$, this may explain why the stannous fluoride group had a relatively less number of teeth with improvement in the severity of the white spots in comparison to the Topacal group. The high concentration of the 
stannous fluoride used may have arrested the lesions preventing any further improvement.

Nevertheless, the white spot lesions were not found to improve significantly between two weeks and four weeks among the three study groups. Oggard et $\mathrm{al}^{(13)}$ elucidated these findings, reporting that in vivo, the remineralization was relatively fast in the first two weeks while after longer periods the remineralization rate was extremely slow.

Another explanation was suggested by Linton ${ }^{(27)}$ assuming that the reduction that occurred in the lesion depth between two and four weeks might have been too small to be noticed clinically and show an obvious change in the severity of the white spot lesions.

Thus a longer period for remineralization of white spots was required to recognize the improvement results visually. This conclusion may clarify the difference in the results obtained by Anderson et al (2006) ${ }^{(29)}$ who found a statistically significant improvement of the clinical white spot lesion (WSL) scores concerning the number of sites that totally disappeared after 12 months when using Topacal C-5 compared to the other group using daily $0.05 \%$ sodium fluoride rinses (65\% vs. $25 \%)$.

It is also worth noting that even the control group showed some improvement in the severity of white spot lesions. This finding was logical as the saliva is known to have a natural remineralizing effect. In the normal oral conditions, there are naturally occurring de and re-mineralization processes continually taking place. The saliva contains all the necessary elements for hydroxyapatite crystal growth. This was confirmed by Oggard et al (1988) ${ }^{(13)}$ who noticed that lesion depth was significantly reduced after debanding and concluded that the remineralizing capacity of saliva in absence of concentrated fluoride was fast.

On the basis of the results obtained in this study we can conclude that:

- Topacal C-5 CPP-ACP is more effective in preventing enamel demineralization than the $0.4 \%$ stannous fluoride gel.

- In addition to its anticariogenic effect, Topacal C-5 seems to have a better remineralizing action than $0.4 \%$ stannous fluoride.

- Topacal C-5 and stannous fluoride had nearly similar effects on the improvement of the scores of the white spot lesions. 
Egyptian

Orthodontic Journal

\section{REFERENCES}

1- Gorelick L, Geiger AM and Gwinnett AJ. Incidence of white spot formation after bonding and banding. Am J Orthod 1982; 1:93-98.

2- Mattingely HA, Sauer GJ, Yancey JM and Arnold RR. Enhancement of Streptococcus mutans colonization by direct bonded orthodontic appliances. J Dent Res 1983; 62 (12):1209-1220.

3- Nasr El-Din MM, Tamish N, Zaher AR and El-Shazly T. Evaluation of the effect of two different adhesives and ligatures on the microflora related to orthodontic brackets. Msc Thesis of Orthodontics, Alexandria University 1997.

4- Ogaard B, Rolla G and Arends J. Orthodontic appliances and enamel demineralization. Part I. Lesion development. Am J Orthod Dentofac Orthop 1988; 94-68-73.

5- Shannon IL and McFarland RA. Chemical preventive dentistry for the orthodontic patient. Int J Orthod 1974, 12:9-14.

6- Boyd RL. Comparison of three self-applied topical fluoride preparations for control of decalcification. Angle Orthod 1993; 63:25-30.

7- Bibby BG, Huang CT, Zero D, Mundorff SA and Little MF. Protective effect of milk against in vitro caries. J Dent Res 1980; 59:1565-70.

8- Rosen S, Min DB, Harper DS, Harper WJ, Beck EX and Beck FM. Effect of cheese, with and without sucrose, on dental caries and recovery of Streptococcus mutans in rats. J Dent Res 1984; 63:894-96.

9- Silva MF, Burgess RC, Sandham HJ and Jenkins GN. Effects of watersoluble components of cheese on experimental caries in humans. J Dent Res $1987 ; 66: 38-41$.

10- Silva MF, Burgess RC and Sandham HJ. Effects of cheese extract and its fractions on enamel demineralization in vitro and in vivo in humans. J Dent Res 1987; 66:1527-32

11- Schupback P, Neeser JR, Golliard M, Rouvet M and Guggenheim B. Incorporation of caseinoglycomacropeptide and caseinophosphopeptide into the salivary pellicle inhibits adherence of mutans streptococci. J Dent Res 1996; 75(10):1779-88. 
12- Reynolds EC, Cai F, Shen $P$, and Walker GD. Retention in plaque remineralization of enamel lesions by various forms of calcium in a mouth rinse or sugar-free chewing gum. J Dent Res 2003; 82(3): 206-11.

13- Oraard B, Rolla G, Arends J and Ten Cate JM. Orthodontic appliances and enamel demineralization. Part 2: Prevention and treatment of lesions. Am J Orthod Dentofac Orthop 1988; 94: 128-8.

14- Delbem AC and Cury JA. Effect of application time of APE and NaF gels on micro hardness and fluoride uptake of in vitro enamel caries. Am J Orthod Dentofac Orthop 2002; 15 (3):169-72

15- Reynolds EC. Remineralization of enamel subsurface lesions by casein phosphopeptide-stabilized calcium phosphate solutions. J Dent Res. 1997; 76:1587-1595

16- Cai F, Shen P, Morgan MV and Reynolds EC. Remineralization of enamel subsurface lesions in situ by sugar-free lozenges containing casein phoshopeptide-amorphous calcium phosphate. Aust Dent J 2003; 48 (4): 240-3.

17- Attia KH and Fayed MS. Effect of phoshoprotein-calcium phosphate complexes on etched demineralized enamel. Egypt Dent J 2005; 51:777-888.

18- El-Kholy As, In vitro study of the effect of glass ionomer cement on early enamel carious lesions. Msc Thesis of Orthodontics, Alexandria University 1998.

19- Hastreteir RJ. Is $0.4 \%$ stannous fluoride gel an effective agent for the prevention of oral diseases? JADA 1989; 118:205-208.

20- Reynolds EC. The prevention of subsurface demineralization of bovine enamel and change in plaque composition by casein in an intra-oral model. J Dent Res 1987; 266: 1120-7.

21- Roberts AJ. Role of models in assessing new agents for caries prevention - Non fluoride systems. Adv Dent Res 1995; 9(3): 304-311.

22- Aimutis WR. Bioactive properties of milk proteins with particular focus on anticariogenesis. J Nutr 2004; 134:989S-995S.

23- Reynolds EC, Riley PF and Storey E. Phosphoprotein inhibition of hydroxyapatite dissolution. Calcif Tissue Int 1982; 34:S52-S56. 
24- Wefel JS and Harless JD. Comparison of artificial white spots by microradiography and polarized light microscopy. J Dent Res 1984; 63(11):1271-75.

25- Shen P, Cai F, Nowicki A, Vincent J and Reynolds EC. Remineralization of enamel subsurface lesions by sugar free chewing gum containing casein phosphopeptide-amorphous calcium phosphate. J Dent Res 2001; 80(12):2066-70.

26- Ten Cate JM and Duijsters PPE. Alternating demineralization and remineralization of artificial enamel lesions. Caries Res 1982; 16:201-10.

27- Linton JL. Quantitative measurements of remineralization of incipient caries. Am J Orthod Dentofac Orthop 1996; 110:590-7.

28- Willmot DR. White lesions after orthodontic treatment: Does low fluoride make a difference? J Orthod 2004; 31(3):235-242.

29- Anderson A, Twetman S, Skold-Larsson K and Petersson LG. Lesion regression with $\mathrm{CPP} / \mathrm{ACP}$-containing cream assessed by laser fluorescence. IADR conference Brisbane 2006 (Abstract). 